\title{
Estimation neutre du cabinet médical
}

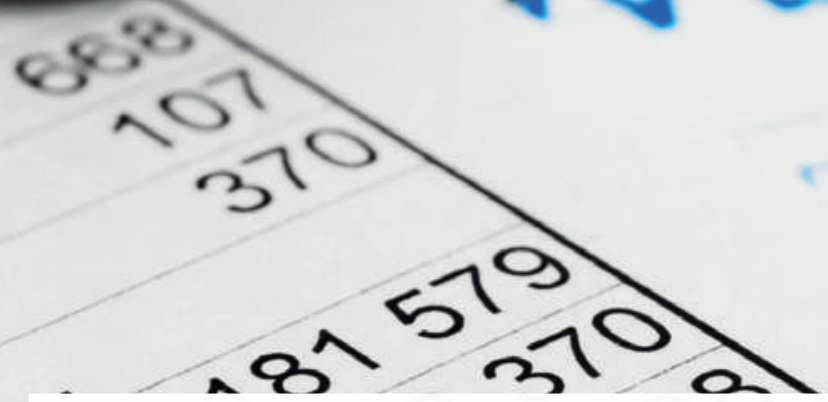

En tant qu'organisation de services du corps médical, nous

- avons une grande expérience, de nombreuses compétences et disposons d'une large reconnaissance

- faisons preuve d'une absolue neutralité, car les acheteurs et les vendeurs sont membres de notre coopérative

- proposons des prix attrayants

- sommes leader sur le marché

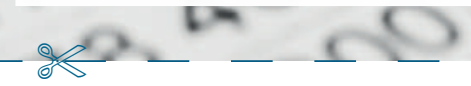

\section{ESTIMATION DU CABINET MÉDICAL}

Je suis intéressé(e). Merci de me contacter.

Prénom / nom

Adresse

NPA / lieu

Date de naissance

Téléphone privé / prof.

Atteignable de préférence vers

E-mail

\section{DOFMH CONSULTiNG}

FMH Consulting Services AG

Burghöhe 1, 6208 Oberkirch

Tél. 0419250077 - Fax 0419210586

mail@fmhconsulting.ch - www.fmhservices.ch 